Boise State University

ScholarWorks

Economics Faculty Publications and

Presentations

Department of Economics

$11-2019$

\title{
Unequal Opportunities and Public Policy: The Impact of Parental Disability Benefits on Child Post-Secondary Attendance
}

Kelly Chen

Boise State University

Lars Osberg

Dalhousie University

Shelley Phipps

Dalhousie University 


\title{
Unequal opportunities and public policy: The impact of parental disability benefits on child post-secondary attendance
}

\author{
Kelly Chen \\ Boise State University \\ Lars Osberg \\ Dalhousie University \\ Shelley Phipps \\ Dalhousie University
}

Abstract. This paper uses Canada's National Longitudinal Survey of Children and Youth to examine whether greater cash transfers available to parents with disabilities when their child was aged 5 to 15 increase the chances that the child will attend post-secondary education (PSE) as a young adult. We exploit differences across provinces and over time in the generosity of provincial disability benefits programs in Canada and find that higher disability benefits when the child was aged 5-15 years old increase the probability that he or she will have attended or be attending PSE by age 19 to 25 . The estimated effect size increases with the severity of the parental disability and the number of disabled parents. Because lower disability benefits significantly worsen performance of public school aged children on standardized math tests and elevate anxiety symptoms, one plausible pathway from disability benefit levels to PSE attendance may be through the cognitive and non-cognitive skills children acquire by the age of 15 . We conclude that the level of disability transfers available early in a child's life mitigates the impact of having a parent with a disability as a source of inequality of opportunity and of unequal probability of PSE participation.

JEL classification: I240, I380, J130, J140

Corresponding author: Kelly Chen, KellyChen@,boisestate.edu

We gratefully acknowledge scholarship support from the Education Policy Research Institute and insightful comments from the editor and three anonymous reviewers. The National Longitudinal Survey of Children and Youth data were accessed through the Atlantic Research Data Centre; we thank Heather Hobson for vetting our output. 


\section{Introduction}

Households headed by adults with disabilities tend to have lower money incomes, greater financial needs and less available free time than other households. Many adults with disabilities are also parents, so these factors influence the long-run opportunities and outcomes of their children. In this paper, we ask whether greater provincial disability benefits during public school years help to alleviate their children's achievement gap in post-secondary education. Despite extensive studies on the employment effects of disability benefits (Bound and Burkhauser 1999; Haveman and Wolfe 2000; Campolieti 2004; Campolieti, Gomez and Gunderson, 2009; Burkhauser, Daly and Ziebarth 2015), very little is known about the implications of disability benefits for the development and well-being of children.

In Canada, poverty risk for adults with disabilities is high and increases with the severity of disability. ${ }^{1}$ Because disabilities reduce employability and hourly wages if employed, they imply lower average labour earnings. Although doctor or hospital bills are not an out of pocket cost in Canada, adults with disabilities nonetheless face significant expenses that are often not publicly funded (e.g., wheelchair ramps, hearing aids, travel to visit specialists and "deductibles" on drugs). Disabilities typically also increase the time required to perform normal household tasks and often impose additional time requirements (e.g., for doctor visits) which other households do not experience.

These income impacts, extra expense burdens and additional time demands inevitably reduce the ability of disabled parents to invest in the goods, services and time helpful for the development of their children (e.g., Mayer 1997). Cross-spouse substitution of parental hours or tasks in child care may be more challenging, and sometimes impossible, in households with a disabled parent. As well, the stress caused by low income and/or traumatic events can in itself have adverse impacts (McLoyd 1990; Conger, Reuter and Conger 2000). Greater time and money stress can make parents irritable, frustrated, less patient, and lacking in the emotional resources needed for supportive and nurturing parenting behaviors - circumstances which are exacerbated when the disabling condition of the parent requires that they themselves may need intense or long-term care. Sometimes the stress induced in families driven by uncertainty of income may go well beyond direct effects of income (Rege, Telle and Votruba 2007; Stevens and Schaller 2010).

It is therefore understandable that studies find evidence of achievement gaps - that children who have spent all or part of their childhood growing up with a disabled parent do less well than their peers on a wide range of outcomes, including high school graduation (Haveman, Wolfe and Spaulding 1991), social, behavioral problems, and personality traits (Morefield 2010; Morefield, Mühlenweg and Westermaier, 2015). These achievement gaps are important examples of inequality of opportunity - and their frequency is quantitatively significant.

Canada's National Longitudinal Survey of Children and Youth (NLSCY) defines disability as a physical or mental condition that impedes a person's usual activities for more than six months. It counts 1.8 million Canadian children under the age of 15 , or about one in six as living with one disabled parent (or more) between 1994 and 2008. Over 70\% of these lived with parents reporting

\footnotetext{
${ }^{1}$ One-third of disabled Canadians had incomes below $60 \%$ of the household-size-adjusted median disposable income over the sample period, less than in Ireland (37\%), Australia and the U.S. (both 45\%) but higher than Denmark, France, Ireland and the U.K (OECD 2010).
} 
This is an author-produced, peer-reviewed version of this article. The final, definitive version of this document can be found online at Canadian Journal of Economics, published by Wiley on behalf of the Canadian Economics Association Copyright restrictions may apply. doi: 10.1111/ caje. 12408

disabilities in more than one functional domain (e.g., at home, at work/school, transition to and from work, in leisure activities or in caring for children). In two parent families, child poverty ${ }^{2}$ is almost twice as high (9.95\%) for children of disabled parents as for children whose parents are able-bodied (5\%). Poverty rates are even higher when parents are restricted in multiple domains $(10.8 \%)$.

Since the NLSCY tracks a child for up to 20 years (e.g., from 5 to 25) we can follow a child in a family where one, or both parents reported a disability during the child's public school years until he or she is a young adult in order to assess longer-term implications for that child's eventual post-secondary education attendance. Figure 1a shows post-secondary education (PSE) participation rates (i.e., whether a youth is currently or has ever been enrolled) for NLSCY youth aged 19-21 by parental functional status when the child was aged 5 to 15. The gap in PSE enrolment between the youth of disabled and able-bodied parents averages at around 4 percentage points ( $9 \%$ of a standard deviation (SD)), increasing by nearly 2 percentage points for each additional functional restriction reported by the parent. Tracking the same youth back in time using longitudinal data, remarkably similar gaps appear to have existed before college entry across developmental outcomes from cognitive achievement (i.e., scores from standardized math tests taken in grades 2 through 10) (Figure 1b) to behavior/emotional well-being (i.e., hyperactive/inattentive and anxiety scales reported for 5-11-year-olds; Figures 1c and 1d), though to a somewhat lesser degree.

Is this achievement gap unavoidable? Since disability benefits available to parents with disabilities vary considerably across Canadian provinces, this paper asks if their level makes a difference to the size of the post-secondary participation gap. In particular, since provincial disability benefits are income-tested and hence more relevant for families with lower socioeconomic status, we focus on families in which neither parent has a university degree. Our continuous difference-in-differences (DD) approach allows us to compare educational attainments of children of parents with disabilities with those of otherwise similar children of non-disabled parents who live in the same province at the same time, so that we net out any unobserved province-specific trends. We test whether the achievement gap in PSE participation - i.e. the difference in the probability of attending college as a young adult - is related to differences in provincial disability benefits available in the province and year when he or she was a child aged between 5 and 15.

Needs-tested disability benefits in Canada are provided by provincial governments, which have complete control over rules and benefit levels, resulting in considerable variation in benefit generosity both across provinces and over time. For example, measuring in \$2008, in 1994 Ontario (at \$15,338) had much higher benefits than Quebec (at \$10,468), but Ontario cut its benefits substantially (by 19\%) in subsequent years, while Quebec kept its rates roughly constant. In 2000, New Brunswick offered even less than Quebec $(\$ 8,337)$ compared to $\$ 14,101$ in Ontario (Table 1).

We use these differences in benefit levels over time and across provinces as identifying variation and assume that a youth's "exposure" to variation in provincial benefit levels when they were younger is independent of other unmeasured determinants of their college-going decision

\footnotetext{
${ }^{2}$ Using Statistics Canada's Low-Income-Cut-Off (LICO) as the unofficial poverty line.
} 
and that the children of disabled parents are more likely to be affected by disability benefit programs than the children of able-bodied parents. Our intention-to-treat estimation strategy uses changes in local benefit rates rather than actual receipt of benefits both because no variable in our data reports the individual household's receipt of disability payments and also because of the well documented reporting bias in welfare incomes in survey data (e.g., Meyer, Mok and Sullivan 2009). Since not all eligible households actually receive the benefits ascribed to them by our imputation, estimates of benefit effects in our study can be considered as lower-bound estimates for the impact of disability benefits. Our three main conclusions are:

[1] Lower parental disability benefits available in a province or year when the child was aged 5-15 have a clear adverse impact on the child's future PSE participation. Our preferred estimates suggest a decline of $1.6-2 \%$ (19-25 years) to 2-4\% (19-21 years) of a SD in PSE attendance rates in response to a $\$ 1,000$ cut in disability benefits. If this effect of disability benefit can be scaled up $^{3}$ a $\$ 3,000$ benefit increase would close more than half of the gap ${ }^{4}$ in PSE participation for the youth of disabled parents relative to their peers of able-bodied parents. While the estimated benefit effects are similar for boys and girls, effect sizes are larger for youth from households with a disabled father. This may be because such households have, on average, lower incomes and so the marginal impact of a transfer gain would be larger than for youth from households with a disabled mother.

[2] It matters when in a child's life the parental disability is assessed and the available disability benefit measured. Breaking child age down into four categories [young (5 to 7 years), preteen ( 8 to 10 years), early adolescent (10 to13 years), adolescent (14 to 15 years)] reveals that higher disability benefits when the child is younger have a larger effect on subsequent PSE attendance than if the observation is later in childhood. This finding reinforces other evidence that economic hardship early in a child's life is particularly harmful to child development (Duncan, Brooks-Gunn and Klebanov 1998; Clark-Kauffman, Duncan and Morris 2003; Duncan, Magnuson and VotrubaDrzal 2014).

[3] Disability benefits affect PSE attendance partially through poorer cognitive and noncognitive skills formation before age 15. Consistent with models emphasizing a dynamic process of skill formation (Cameron and Heckman 1998; Keane and Wolpin 2001; Carneiro and Heckman 2002), we find lower disability benefits were already associated with worse performance in a standardized math test and with elevated anxiety symptoms during the earlier childhood of the same young adults we analyze, which suggests that the influences of low disability benefits cumulate over time.

To the best of our knowledge, the research presented in this paper is the first to estimate the longer-run impact of parental disability benefits. In Chen, Osberg and Phipps (2015), we found that the current level of provincial disability benefits affected the anxiety and inattentive/hyperactivity of 4 to 11 year old children and math scores of children in grades 2 through 10. However, that study could not address the issue of whether those findings are just evidence of a temporarily tougher childhood or whether having a parent with a disability has longer

\footnotetext{
${ }^{3}$ For more details see Footnote 24.

${ }^{4}$ Given the gap in PSE attendance between the youth of disabled and non-disabled parents in our sample is 6.7 percentage points (Table 3), the calculation, using the number of domains in which the parent is limited as a proxy for eligibility is: $(0.01 \times 1.5 \times 3 / 0.067=0.67)$ for $19-21$ year olds for instance.
} 
terms impacts which affect lifetime wellbeing. In this paper, we follow children/youth for up to 10 years, from ages 5 to 15 to ages 19 to 25 in order to assess implications of parental disability benefits for children/youth's eventual post-secondary attendance.

As well, this research introduces three more nuanced measures of parental disability, and hence benefit eligibility, than in our previous work to better define the intention-to-treat population. The new measures not only enhance the internal validity of the study and cross-validates our previous findings, but also allows us to test hypotheses such as whether the benefit effect increases with the number of domains in which a parent is restricted and/or the number of disabled parents).

The paper is divided into seven parts. The next section reviews earlier literature and discusses the Canadian institutional background. Sections 3 and 4 introduce the data and empirical strategies used. The main results, pathways, and heterogeneity in estimated treatment effects are examined in Sections 5-7. Section 8 discusses results and possible policy implications.

\section{Background}

\subsection{Previous Studies}

The impact on child life chances of public transfers to households with children has been examined previously (e.g., Mayer 1997; Cooper and Stewart 2013), but not, so far as we are aware, in the context of parental disability benefits (aside from our own past work Chen, Osberg and Phipps, 2015). While the estimated effect size varies, a common finding is that income-boosting policies make more difference to the households at the bottom of the income distribution than at the top, and that gains are more pronounced for cognitive and schooling outcomes than for behavioral and emotional development. Besides school success, long-term beneficial impacts of cash transfers to poor families have been documented for children's nutritional status, longevity and income in adulthood (Aizer et al. 2014), criminality for minor offenses (Akee et al. 2010) and personality traits and behaviors (Akee et al. 2015).

Evaluation studies on welfare reforms in the 1990s U.S. have provided experimental and/or quasi-experimental evidence. Examining the Minnesota Family Investment Program, Gennetian and Miller, (2002) and Morris and Gennetian, (2003) find that increased income of lone mother families randomly assigned to the treatment group leads to improvement in children's academic performance, school engagement, and positive social behaviour. Duncan, Morris and Rodrigues (2011) and Clark-Kauffman, Duncan and Morris (2003) both focus on educational outcomes, and both find significant positive effects of transfer income on school achievement for programs that increase income. Fernald, Gertler and Neufeld (2008) evaluate the Mexican Opportunidades, a conditional cash transfer program, and conclude that a doubling of cash transfers for low-income communities randomly enrolled in the program had significant favorable effects on both health and cognitive outcomes, such as children's cognitive development, height-for-age, BMI-for-age, and the proportion of being stunted and overweight.

Existing evidence consistently identify larger transfer effects for relatively low-income households. In the Canadian context, Milligan and Stabile (2011) simulate the beneficial impact on children's mathematics and reading scores of the National Child Benefit. Akee et al. (2010) argue that an exogenous increase in family income, due to the opening of a casino on an Eastern Cherokee reservation in rural Carolina, played a significant role in children's eventual educational attainment as young adults. 
This is an author-produced, peer-reviewed version of this article. The final, definitive version of this document can be found online at Canadian Journal of Economics, published by Wiley on behalf of the Canadian Economics Association Copyright restrictions may apply. doi: 10.1111/ caje. 12408

For both cognitive and behavioural outcomes, impacts appear to differ across the childhood age span - specifically, the first five to six years of childhood seem to be most important. ClarkKauffman, Duncan and Morris (2003) for instance find children assigned to family-incomeboosting programs saw significant improvement in cognitive development 2-5 years after their parents' entry into the programs, but only for children 0-5 at the beginning of these studies. Votruba-Drzal (2006) presents similar evidence that only during early childhood (1-6 years) was income significantly associated with change in child math and reading skills, although during middle childhood (6-12 years) income is more strongly associated with a reduction in behavioural problems.

Our paper builds on this literature by investigating the implications for children of transfer programs targeted on people with disabilities. As the OECD (2010) documents, such programs are one of the most common, and largest, social spending programs in industrialized countries - but although labor supply effects have been examined in the literature, very little is known about other impacts on co-resident family members.

\subsection{Disability Benefits in Canada}

In Canada, needs tested disability benefits are delivered either through the disability component of provincial social assistance programs (Newfoundland and Labrador, Nova Scotia, New Brunswick, Manitoba,) or through provincial disability support programs that specifically target the disabled (Alberta, British Columbia, Ontario, Quebec, Alberta and PEI). Survey of Labor and Income Dynamics data (Crawford, 2013) indicate that the single largest component of the incomes of working-age (16-64) poor Canadians (i.e., below the LICO) with disabilities is social assistance (35.3\%), followed next by federal and provincial child benefits $(9 \%)$ and the Canada and Quebec Pension Plans (C/QPP) (8.9\%).

Provincial disability benefits provide needs-tested income assistance for people with disabilities who are either ineligible for other benefits or for whom other benefits received are inadequate (e.g., C/QPP disability benefits, the Guaranteed Income Supplement, the Spouse's Allowance, Allowance for the Survivor, or War Veterans Allowance). ${ }^{5}$ Eligibility for provincial programs requires a needs-test, an asset test ${ }^{6}$ and medical evidence of a work limiting disability. ${ }^{7}$ Benefits are offset dollar-for-dollar with unearned income (e.g., interest income, pensions, or other needstested transfer income) and earned income that is not exempt. ${ }^{8}$ During our observation period, only

\footnotetext{
${ }^{5}$ Disability benefits typically consist of a basic allowance intended for food, clothing, utilities, personal and household items and a shelter allowance intended for rent or mortgage. Some provincial programs also provide extra benefits for special needs, such as drug and dental coverage, vision care, medical transportation, diabetic supplies, assistive devices, mobility device repairs and batteries.

${ }^{6}$ All provincial programs over sample period exempted most fixed assets, such as principal residence, vehicles (up to a value limit), the value of prepaid funerals and property/equipment required for employment. Liquid asset exemptions vary by province.

${ }^{7}$ As shown in Online Appendix Table 1, all provincial programs require applicants to submit a medical certificate completed by a licensed physician indicating the level of the impairment and the potential for rehabilitation; and all provinces require proof that the disability has a substantial impact on the potential recipient's usual activities and occur on a continuous or recurrent basis (e.g., last for at least 3-12 months). Along with the medical certification requirement, an applicant must be between 18 and 65 and be resident of particular province to be eligible.

${ }^{8}$ All programs over sample period exempted a portion of employment income although using slightly different formulae. For example, Nova Scotia allowed its client families to keep the first \$200 of earned total income and one-fourth of earnings exceeding $\$ 200$ per month.
} 
This is an author-produced, peer-reviewed version of this article. The final, definitive version of this document can be found online at Canadian Journal of Economics, published by Wiley on behalf of the Canadian Economics Association Copyright restrictions may apply. doi: 10.1111/ caje. 12408

one province changed its basic earnings exemption level. ${ }^{9}$ Importantly, in all of the provincial programs earnings exemptions and asset limits are not automatically indexed for inflation.

Prior to 1996, the federal government through the Canada Assistance Plan (CAP) offered a matching grant for provincial spending which funded $50 \%$ of the benefits for all provincial programs. After 1996, a block grant (i.e., the Canada Health and Social Transfer) replaced CAP, and substantially reduced the federal government's contributions. In response, provinces enacted a variety of changes, reducing welfare benefit levels, tightening eligibility requirements, and imposing work requirements on welfare recipients. We utilize the changes in benefits over the post 1996 period to estimate the effects of parental disability benefits on the gap in post-secondary attendance.

Table 1 shows the maximum real annual disability benefits (2008 \$) for a single individual under ten provincial programs for the NLSCY survey years, and measures of both cross-section and time-series variations in benefit schedules. On average, Ontario, Alberta, British Columbia and Quebec offered the highest annual benefit level at \$13,385, \$12,803, \$11,096 and \$10,481 per person, respectively, whereas the benefits were lowest in New Brunswick, Manitoba and Nova Scotia, which paid $\$ 8,685, \$ 9,540$ and $\$ 9,971$ per person annually. In all provinces, the real value of disability benefits decreased over time (PEI, Nova Scotia, New Brunswick, Ontario, Manitoba and Saskatchewan), or remained roughly constant (Quebec, British Columbia and Newfoundland. $)^{10}$

\section{Data Description}

This paper uses Canada's 1994-2008 National Longitudinal Survey of Children and Youth, (NLSCY) combined with province-level data capturing variations in youth unemployment, educational expenditure per capita, school entering age, and disability benefit generosity in the province of residence. The NLSCY began in 1994 with a nationally representative sample of children (22,831 children) between 0 and 11 years old. The same children were then surveyed at two-year intervals up to the age of 25. At each survey year, a new cohort of children aged 0-1 was added to the longitudinal population. The unit of analysis for the NLSCY is the child, but questions about the child's social, emotional and behavioral development and the family are asked of the "person most knowledgeable" (PMK) about the child (the mother for over $90 \%$ of our sample) for young children; both parent and child answer questions from age 10 to 18; only the youth is surveyed after age 18. An important advantage of the NLSCY is thus that information on youths' lives is collected regardless of whether they leave their parental homes.

This study examines whether a youth participates in post-secondary education either right after high school (i.e., ages 19-21) or after a subsequent "gap year (or years)" as a young adult (i.e., ages 19-25). We exclude18-year-olds since some may still be attending high school. We define a

\footnotetext{
${ }^{9} \mathrm{PEI}$ increased its basic earnings exemption level from $\$ 600$ to $\$ 900$ per month in 2001 .

${ }^{10}$ In some provinces, actual entitlement to disability benefits may vary according to the circumstances of individual families, including household size, composition and the children's age. We do not differentiate these family types both because of data limitations and to avoid potential endogeneity in fertility decisions and living arrangements to the generosity of needs-tested benefits (Moffitt 1990; Milligan 2005). We are unaware of any systematic legislation change that differentially affected benefit schedules for single persons. This paper thus exploits within-province variations in benefit levels for the single disabled over time, which reflects changes in benefit levels for other family types.
} 
youth to be a "post-secondary attendee" if he/she reports being currently enrolled or having previously been enrolled and/or completed any type of schooling higher than high school, including two-year colleges, Quebec's CEGEP, or four-year universities. As a result, the probability of post-secondary enrolment we analyze is unconditional on information about high school graduation, and can be seen as the total effect of parental disability on the joint event of high school completion (or equivalent) and post-secondary enrolment.

\subsection{Parental Disability}

A unique feature of the NLSCY relative to other population surveys in Canada is that it provides information about the health of both parents and their children. For example, in 1994, 2000, 2002, 2004, 2006 and 2008, the PMK was asked the following questions for her/himself and (where applicable) her/his spouse/partner: "Because of a long-term (i.e. a condition or problem that lasts for more than six months) physical or mental condition or a health problem, are/is ...XXX.... limited in the kind or amount of activity you/he/she can do: 1) At home? 2) At school or at work? 3) In other activities such as transportation to or from work or leisure time activities? 4) In caring for children?"11 Because our analysis employs an intention-to-treat approach, we construct four different measures of parental disability, and hence benefit eligibility: 1) two "incidence" measures that indicate for each child/youth whether either parent has any restriction and whether either parent has a work-limiting disability, and 2) two "severity" measures that count the number of domains in which a parent is restricted ${ }^{12}$ and the number of parents with a work-limiting disability. The latter constitute proxies for the severity of disability to the extent that more severe conditions lead to more restrictions. Because access to provincial disability benefits requires medical proof of a work-limiting disability, parents who report they are limited in other areas of economic life but not in work are by definition not eligible for benefits. The intention-to-treat population thus might be better defined as those who report being limited at work. However, the exact type of limitation people report may change over time as either the condition or life circumstances (e.g., type of job the respondent holds) evolve. To account for both possibilities, we implement our analysis using all four measures. ${ }^{13}$

\footnotetext{
${ }^{11}$ Unfortunately, this question was not asked in 1996 or 1998.

${ }^{12}$ We use the number of limitations reported for whomever has the higher count in the household in the case where both parents are disabled, since the "severity" measure is, for each parent, an ordinal ranking of severity which is not necessarily nicely additive in the same way as cardinal numbers (e.g., for income). [Two parents each with a mild disability do not necessarily have the same total limitations as one parent with a severe disability]. For families where both the mother and the father are disabled, we therefore focus on the higher count of limitations reported for one parent.

${ }^{13}$ A potential advantage of using the intention-to-treat treatment status is that it is unlikely to be affected by economic incentives (i.e., to gain access to benefits). For example, there is evidence suggesting that the self-reported presence of a work limitation may increase for workers in redundant industries or for older workers during periods of high unemployment (Haveman and Wolfe 2000). Nevertheless, we tested for the possibility that respondents misreport disability status when the disability benefit level is high as a justification for other behaviors by estimating a linear probability model for our broadest measure of benefit eligibility as a function of the benefit level, while controlling for the same set of controls as in our most comprehensive model. We find no evidence of a relationship between benefit levels and the reported incidence of parental disability.

Given a disabling condition, an individual may be deemed eligible in one province but not another, depending on the stringency of the screening process. We compare the number of cases for the largest four provinces (Alberta, British Columbia, Quebec and Ontario) against the level of the benefit prevailing at the same time (see Online Appendix Table 2). Over time, benefit generosity declined and the caseloads of all four programs saw significant increases, which may imply that gatekeepers tend to get more "lenient" when the benefit level is lower. A linear regression of the caseload against the benefit level while controlling for province
} 


\subsection{Sample Construction}

Using the fact that the NLSCY is longitudinal, we select a sample of children/youth for whom we have: 1) an assessment of parental disability status at some point during the child's public school years (5 to 15); and, 2) for the same child/youth, self-reported attendance in PSE during young adulthood (using two windows of observation - while aged $19-21$ or while $19-25$ ). For the narrow window of observation, we observe the PSE participation of three cohorts of children cohort A who were 5-7 years old in 1994 and 19-21 in 2008, Cohort B who were 7-9 in 1994 and 19-21 in 2006 and Cohort $C$ who were 9-11 in 1994 and 19-21 in 2004 (see Online Appendix Table 3). In our largest pooled sample, the same child can thus appear more than once. ${ }^{14}$ For the broader window of observation (PSE enrolment when aged 19 to 25), our data can be summarized as in Online Appendix Table $4 .{ }^{15}$ Clearly, this broader window introduces more possible combinations and hence increases our pooled sample size. Note, however, that the same children are used to construct the two samples.

These pooled samples maximize sample size but since they may have repeated observations on the same youth (depending on his or her birth cohort) we test that our results are robust to sample composition by 1) replicating our analysis randomly keeping just one observation for each youth, and 2) regressing child outcomes against the average level of benefits the parents were exposed to during the period when the child was 5-15, and the average degree of disability, while controlling for the number of earlier periods for which information on disability is available. As we show below, results are not substantively affected.

In addition, to avoid confounding the effect of parental disability benefits with that of being in a single-parent/guardian home or with a youth's own health problems we restrict analysis to youth living in two-parent families and youth who do not report disabilities for themselves, which reduces sample size by $15 \%$. To the extent that poor-benefit-induced stress may increase the probability of divorce/separation and parental divorce/separation may have an additional negative impact on PSE attendance, this practice likely leads to under-estimation of the total impact of parental disability benefits. Furthermore, because the purpose of this study is to estimate the potential impact of social assistance programs, we examine only the subset of families most likely

dummies reveals a slope coefficient of $(-17.8)(\mathrm{p}=0.013)$. All else being equal, if, on average, applicants who were admitted into the programs were of better health over time (given that benefit levels declined over time), this would imply a potential understatement of the true benefit effect in our context. Therefore, even with this likely downward bias, our estimates suggest a beneficial impact of parental disability benefits on the well-being of children.

Yet another potential concern, given that the mother is the PMK for over $90 \%$ of our sample, is that we are mostly using a selfreport for the mother's condition and a proxy report for the father's condition (Burton, Lethbridge and Phipps 2007). While proxy reports are less desirable than self-reports, if women know less about the true state of their spouses' health than about their own, they nonetheless constitute an accepted measure (e.g., Medical Research Council Cognitive Function and Ageing Study, 2000). Furthermore, given that the activity limitation measures we study are relatively severe, the questions are less ambiguous than questions such as "how is your health in general?", which reduces the potential for reporting bias.

${ }^{14}$ For Cohort A, parental disability status is observed 3 times during the 5 to 15 window and we can construct 3 observations: 1) combining parental disability and provincial disability data from age 5 to 7 with PSE attendance at age 19,2) combining data at age 11 to 13 and PSE attendance at age 19 to 21, and 3) combining data from 13 to 15 and attendance data from 19 to 21 . Potential combinations for children from cohorts B and C are also illustrated in Online Appendix Table 3.

${ }^{15}$ This broader window of observation for PSE attendance sometimes creates missing data issues for the observation of parental disability. For example, for Cohort D (age 5 in 1994) we only observe in 2002 parental disability for children who were then 13. The parental disability status of the full 19 to 25 cohort from 2008, 2006 and 2004 is observed in 1994, but at differing ages - 5 to 11,7 to 13 and 9 to 15 , respectively. 
to be eligible for the disability benefits - those where neither parent has a university degree and both are between 18 and 65 years in the first observation. Finally, to ensure comparability of coefficients across models, we exclude those for whom information on any variable is missing. ${ }^{16}$

In the end, we obtain 5,400 and 7,900 observations for the two age range samples, 19-21 and $19-25$, respectively, constructed using data for approximately 2,200 individual children. ${ }^{17}$

\subsection{Descriptive Statistics}

Panel A of Table 2 shows the incidence of parental disability for youth aged between 19 to 21 years in the NLSCY. The patterns found for the youth aged between 19 and 25 are much the same. Overall, at least one parent reports a disability for $16 \%$ of our pooled samples. In over $70 \%$ of these cases, parents indicated activity restrictions in more than one functional domain (e.g., home; work/school; transition to and from work; caring for child). ${ }^{18}$ Around $60 \%$ reported being limited at work or in school.

To put these figures into perspective, Panel B of Table 2 provides comparative national averages on the incidence of disability from the 2012 Canadian Survey on Disability (CSD), the most recent available survey of adults with disabilities in Canada. The 2012 CSD uses questions on activity limitation similar to those used in the NLSCY to identify persons with disabilities among respondents in the 2011 National Household Survey (NHS), who were 15 years of age or older as of the date of the NHS. ${ }^{19}$ It also develops a global severity score based on disability types, the frequency of the activity limitations (never, rarely, sometimes, often, or always) and the intensity of the difficulties (no difficulty, some difficulty, a lot of difficulty, or cannot do), and classifies the score into four severity classes (Statistics Canada 2015). As shown, despite the differences in population coverage and sampling weights, since the unit of analysis of the CSD is anyone over the age of 15 whereas our unit of analysis is a youth with parents aged less than 65, and although we consider domains of restriction rather than frequency of restriction, the rates of disability in the two panels match each other reasonably well.

\section{Empirical Strategy}

Our study considers changes in real benefits under the ten provincial disability benefit programs to be a source of exogenous variation, and uses a continuous DD method to estimate the causal

\footnotetext{
${ }^{16}$ Due to non-response to the PSE status question, around $10 \%$ of youth with demographic or parental disability information available are excluded. This could introduce a sample selection bias if youth with missing data are systematically different from those with complete information. To address this concern, we estimated linear probability models of the probability of nonresponse to the PSE attendance question. Overall, older youths or those whose mother was older at the time of the survey are less likely to respond. The non-response rate also tends to be higher for those who lived in step families, and for those whose father had lower education. Conditional on these covariates, however, we find no systematic difference in non-response about PSE attendance between the children of disabled and non-disabled parents across benefit levels.

${ }^{17}$ To minimize potential disclosure risk, Statistics Canada requires us to report all sample sizes randomly rounded to base 10.

${ }^{18}$ Note that a parental disability can be life-long (e.g., deaf), last several periods (e.g., hip replacement surgery) and/or can exist in just one period. A limitation of our analysis is that we cannot distinguish these cases.

${ }^{19}$ Specifically, all persons who answered yes to one of the following NHS filter questions on activity limitations are included in the CSD frame: Does a physical condition or mental condition or health problem reduce the amount or kind of activity this person can do: 1) at home? 2) at work or at school? 3) in other activities, for example, transportation or leisure? Does this person have any difficulty hearing, seeing, communicating, walking, climbing stairs, bending, learning or doing any similar activities? (Statistics Canada 2014)
} 
This is an author-produced, peer-reviewed version of this article. The final, definitive version of this document can be found online at Canadian Journal of Economics, published by Wiley on behalf of the Canadian Economics Association Copyright restrictions may apply. doi: 10.1111/ caje. 12408

impact of parental disability benefits on children. Because unmeasured province-specific transitory shocks could be correlated with benefit generosity and children's educational outcomes, we use the children of non-disabled parents living in the same province at the same time as primary controls. Hence, we examine whether the outcome gap - i.e., the difference in post-secondary participation between children of disabled and non-disabled parents - is related to benefit changes across provinces and over time. Since the level of disability benefits is determined by provincial legislation and can only affect child achievement indirectly through changes in individual families' financial circumstances, positive associations between changes in benefit generosity and the outcome gap in later observed PSE enrolment will imply that increasing parental disability income assistance improves the probability of their child attending PSE.

Specifically, we first estimate two versions of an "incidence" model for each window for PSE enrolment, 19-21 and 19-25:

$$
\begin{aligned}
& \quad P S E_{i p t, a}=\beta_{0}+\beta_{1} D I S_{i p t, 5 / 15}+\delta D I S_{i p t, 5 / 15} \times B E N_{p t, 5 / 15}+X_{i p t, 5 / 15}^{\prime} \eta+Y_{i p t, a}^{\prime} \theta+\lambda_{p}+ \\
& \kappa_{t}+\sigma_{p t}+\epsilon_{i p t}
\end{aligned}
$$

where $a$ indexes the PSE enrolment window (19-21 and 19-25), i the youth, $t$ the survey year, and $\mathrm{p}$ the province. $P S E_{i p t, a}$ is the youth's PSE attendance. In this incidence model $D I S_{i p t, 5 / 15}$ is an indictor representing whether either parent has any restriction or whether either parent has a worklimiting disability. $B E N_{p t, 5 / 15}$ is the real maximum disability benefit available in January of the previous calendar year. $X_{i p t, 5 / 15}$ is a vector of child- and family- characteristics observed at the time of parent's disability (e.g., child age, relative age for grade, ${ }^{20}$ gender, number of siblings, family structure (step vs "intact" family), both parents' ages and age squared, immigration status, levels of education (less than high school; high school graduate; and post-secondary diploma or some post-secondary education but not a degree), and interaction terms between both parents' education and disability statuses, while $Y_{i p t, a}$ is a vector of control variables capturing the changing family circumstances of the youth by 19/25 (i.e. number of siblings and family structure) and the age when PSE was reported. ${ }^{21}$ In this regression, $\lambda_{p}$ includes dummy variables for each of the ten Canadian provinces, while $\kappa_{t}$ includes dummy variables for years. The province fixed effects hold constant unmeasured permanent differences across provinces - for example, the availability of postsecondary institutions and programs, regulations about earnings exemptions and asset limits, cost of living, the degree of discrimination against disabled people, or other disability-related services. The year fixed effects hold constant any time trends that affect all provinces similarly, such as the 2004 changes in the federal disability tax credit.

It is, of course, possible that other province-level factors change over time and simultaneously affect both child educational attainment and disability benefit generosity. If these changes coincide with changes in disability benefits, bias in our estimates could result. To account for this

\footnotetext{
${ }^{20}$ Relative age for grade is a dummy variable capturing if the child's birth date puts him/her in the younger half of his/her class given the school-entry legislation in that year and province. While all children enter grade one in the year they turn 6 over sample period, the school entry age cut-off date varies across provinces and over time (Chen, Fortin and Phipps 2015).

${ }^{21}$ Importantly, since family income can be influenced by the size of the benefit, and determines eligibility for social assistance benefits, we leave it out of the equation to avoid the introduction of a mechanical endogeneity.
} 
possibility, we estimate all models with province-year fixed effects $\left(\sigma_{p t}\right)$. Consequently, any variables that fluctuate by province and year are implicitly controlled, and therefore unidentified in the model. ${ }^{22}$

The coefficient of interest is $\delta$ - if a higher parental disability benefit increases the probability of attending PSE of children with disabled parents, we expect to see a positive and statistically significant $\delta$, indicating that when benefits are higher the gap in PSE enrolment between the youth of disabled and non-disabled parents in the same province narrows.

As an alternative way of defining the intention-to-treat population, we also estimate two versions of a second "severity" model exploiting the dose effect of the treatment:

$$
\begin{aligned}
& P S E_{i p t, a}=\beta_{0}+\beta_{1}\left(\sum_{n=1}^{j} D I S_{n}\right)_{i p t, 5 / 15}+\delta\left(\sum_{n=1}^{j} D I S_{n}\right)_{i p t, 5 / 15} \times B E N_{p t, 5 / 15}+X_{i p t, 5 / 15}^{\prime} \eta+ \\
& Y_{i p t, a}^{\prime} \theta+\lambda_{p}+\kappa_{t}+\sigma_{p t}+\epsilon_{i p t} .
\end{aligned}
$$

Here $\mathrm{j}$ counts the number of domains of restriction for the parent with the larger number of restrictions, or the number of parents with a work-limiting restriction. Correspondingly it can take a maximum value of 4 and 2, respectively (for more details see Section 3.1). If the likelihood and amount of benefit payments actually received by individuals increase with the degree of disability and/or the number of parents with work-limiting disabilities, ${ }^{23}$ model (2) effectively tests whether a given benefit cut has a greater adverse impact on PSE enrolment for youth of disabled parents who are most likely eligible for benefits because they have the most severe conditions. We therefore treat model 2 as our preferred specification,

Since this study uses an intention-to-treat design, we are examining whether a change in benefit generosity during their earlier childhood has an impact on the population most likely to be affected (i.e., college age children of disabled parents with low education). Because the analytic sample includes ineligible disabled parents as part of the treated group and not all eligible parents in fact received the benefits ascribed to them, $\delta$ understates the true impact of parental disability benefits. $^{24}$ The advantage of using likely eligibility for benefit payments, rather than the actual receipt, is that it avoids the danger that results will be biased upwards, since differences in reported income may be associated with unobserved household characteristics.

Throughout the analyses, we employ longitudinal sampling weights to take account of the nonresponse bias and the sample design. Therefore, our results are representative of the longitudinal cohorts of 5-11 year olds in 1994. Standard errors are clustered at the province level. Because the number of clusters is relatively small and vary appreciably in size, we use wild cluster bootstrapped t-statistics based on Cameron, Galback and Miller (2008) to correct potential biasedness (MacKinnon and Webb 2017). ${ }^{25}$

${ }^{22}$ An alternative DD specification that controls for benefit, disability status, interaction, province and year fixed effects produces highly similar results.

${ }_{23}$ The time and financial demands certainly vary by the nature of the disability, but in general would be expected to be greater when the condition is more severe (Gould 2004).

${ }^{24}$ See the Online Appendix B for discussion of the take-up rate of means-tested disability benefits in Canada.

${ }^{25}$ All inferences were carried out using the Stata routine by David Roodman (Roodman et al. 2018). 
This is an author-produced, peer-reviewed version of this article. The final, definitive version of this document can be found online at Canadian Journal of Economics, published by Wiley on behalf of the Canadian Economics Association Copyright restrictions may apply. doi: 10.1111/ caje. 12408

\section{Overall Effects of Parental Disability Benefits on PSE Attendance}

Table 4 shows estimated effects of parental disability benefits on PSE attendance. Results are consistent across alternative specifications - i.e. for the two windows of observation: 19-21 years (left panel; 5400 observations) and 19-25 years (right panel; 7900 observations) and for the 4 disability measures described above: 1) incidence of any restriction (columns 1 and 5); 2) incidence of a work-limiting restriction (column 2 and 6); severity measured as number of restricted domains experienced by the parent with most restrictions (columns 3 and 7) and severity measured by the number of parents with work-limiting disabilities (columns 4 and 8). All regressions control for year, province, and province-by-year fixed effects.

Across disability measures and data samples, there is strong evidence that a lower parental disability benefit reduces PSE participation - the interaction term is in all specifications statistically significant at high levels of confidence, of appropriate sign and with an empirically meaningful magnitude. Measuring benefit eligibility using the presence of any restriction by either parent (columns 1 and 5), a $\$ 1,000$ reduction in real disability benefits ${ }^{26}$ causes a decline in PSE enrolment by $4.9 \%$ and $3.8 \%$ of a SD by the ages of 21 and 25 , respectively. The effect size is smaller for the broader window of observation, suggesting that while youth tend to return to postsecondary education over time, ${ }^{27}$ this is a bit more likely for the children of disabled parents. Focusing on the incidence of a work-limiting disability (columns 2 and 6) leads to slightly strengthened results for both windows of observation $(5.7 \%$ of a SD by 21 and $4.9 \%$ by 25$)$.

Switching attention to the severity measures (columns 3-4 and 7-8), the adverse effect of lower disability benefits on PSE attendance is greater for children whose parents face more limitations and for families where both parents have work-limiting disabilities. Holding benefit level constant, each additional restriction experienced by a parent increases the benefit impact by $2 \%$ and $1.6 \%$ of a SD by 21 and 25 years, respectively. In other words, a $\$ 1,000$ increase in benefit level would boost the probability of participating in PSE by $8 \%$ (by age 21) and $6.4 \%$ (by age 25) of a SD for a youth of parent reporting restriction in all four domains. Relative to youth in families where one parent experiences a work-limiting disability, the magnitude of the estimated benefit effect on PSE attendance rises by $4.1 \%$ (by age 21 ) and $2 \%$ (by age 25 ) of a SD for youth living with two disabled parents. Overall, the effect size of a $\$ 1,000$ increase in the benefit level is $6.4-12.6 \%$ (by 21 ) and $6.5-11.2 \%$ (by 25 ) as large as the step-family association for youth.

The DD approach requires the assumption that the gap in PSE enrollment between the most likely eligible and least likely eligible youth of disabled parents remains the same in the absence of a benefit cut within province. Sensitivity checks to assess validity of this assumption are discussed in Online Appendix A. First, we re-estimate our basic model using a more advantaged group - i.e., youth with one or both parents university-educated. Second, we run a set of placebo regressions replacing the disability benefit variable with, or additionally controlling for alternative variables that vary by province-year and also affect child achievement: 1) provincial unemployment rate among youth under 25, and 2) "education spending per capita" - provincial spending on public and private elementary and secondary education per school-age child. Third, we augment our original model with some long-term or cultural factors suggested in the literature

\footnotetext{
${ }^{26}$ In our regression analysis, the disability benefit variable is measured in 1,000 dollars.

${ }^{27}$ Lefebvre and Merrigan (2008) find that youth are more likely to attend college over time using the NLSCY data.
} 
This is an author-produced, peer-reviewed version of this article. The final, definitive version of this document can be found online at Canadian Journal of Economics, published by Wiley on behalf of the Canadian Economics Association Copyright restrictions may apply. doi: 10.1111/ caje. 12408

as important determinants of PSE participation (Finnie, Mueller and Sweetman 2010). These variables include the child's ethnicity, family wealth, and French minority, and could be correlated with benefit eligibility, potentially causing omitted variable bias. Fourth, we explore the role of sample composition by replicating our analysis for the subsamples that randomly keep only one observation for each youth. As an alternative strategy to simply taking one observation from each child, we also model the benefit generosity as well as eligibility by the average level of benefits the parents are exposed to during the period when the child was 5-15 and the average degree of disability, while controlling for the number of earlier periods for which information on disability is available. Overall, we find little evidence suggesting that our results are driven by correlated polices, sample composition change, or unobserved heterogeneity associated with parental disability at the household level.

\section{Pathways}

Previous research on determinants of PSE enrolment and the dynamic process of skill formation (Carneiro and Heckman 2002; Keane and Wolpin 2001; Todd and Wolpin 2006) finds that factors influencing PSE enrolment are often entangled, and may be largely determined long before the actual point of entry into higher education. ${ }^{28}$ Given that our own earlier research found that disability benefits affected outcomes of young children (Chen, Osberg and Phipps, 2015), we examine the hypothesis that one pathway from parental disability benefits to children's PSE participation may be through earlier cognitive and non-cognitive development (Cameron and Heckman 1998; Cunha, Heckman and Schennach 2010). Specifically, we study standardized math scores, parent-reported hyperactive/inattentive behaviours and emotional anxiety symptoms, all of which were reported in earlier cycles of the NLSCY for the same children/youth.

The math test in the NLSCY is designed to measure a child's basic competencies in math (e.g., addition, subtraction, multiplication and division of integers is a shorter version of the Mathematics Computation Test taken from the Canadian Achievement Test, $2^{\text {nd }}$ edition with scores ranging from 0 to 750 and is administered to children in grades 2 to 10 every survey year. The hyperactivity and emotional anxiety scores are derived from statements by the PMK. ${ }^{29}$ Because the hyperactivity and anxiety questions were only asked to parents of children aged under 11 in the NLSCY, the youth with hyperactivity and anxiety scales measured at more than one time point are those aged 5 years in 1994 and 11 years in 2000 for both the 19-21 and 19-25 age range samples. This reduces variation in benefit levels substantially and may pose a challenge in accurately identifying benefit

\footnotetext{
${ }^{28}$ Using the 1979-91 waves of the U.S. National Longitudinal Survey of Youth, Heckman and Cameron (2001) find that differences in family income crystalized in the child's scholastic ability as measured by the Armed Forces Qualification Test largely account for differentials in measured schooling attainment. Frenette (2007), using data from the Canadian Youth in Transition Survey (YITS) (Cohort A) of Canadian youth, shows that differences in standardized test scores in reading or mathematics and science obtained at age 15, school marks reported at age 15, parental influences, and high-school quality account for $84 \%$ of the total gap in university attendance between youth from the top and bottom income quartiles.

${ }^{29}$ For Hyperactivity, about the child having trouble sitting still or being restless, being easily distracted, being inattentive, having trouble sticking to any activity, concentrating, paying attention for long, being impulsive, acting without thinking, having difficulty waiting for his turn in games or groups. The emotional anxiety score is derived from six statements about the child being unhappy or sad, not as happy as other children, fearful or nervous, worried, crying a lot, being high strung or tense, having trouble enjoying himself or herself. For each behavior, the parent can choose: "never or not true" $(=0)$; "sometimes or somewhat true" (=1); or, "often or very true" $(=2)$. Responses are summed to construct a scale ranging in value from 0 to 14 , with a high score indicating the highest level of inattentive /hyperactive or anxiety behavior.
} 
effects. We thus are inclined to base our interpretation on the results from math test scores for robustness reasons.

Table 5 reports results for standardized math test scores, emotional anxiety and inattentive/hyperactive for the two windows of observations. ${ }^{30}$ There is a significant and positive association of benefit changes with math test score and a significantly negative relationship between the benefit generosity and emotional anxiety symptoms (where a higher value indicates worse outcome). Using our preferred eligibility measures, a $\$ 1,000$ benefit cut reduces the math test score by $1.5-3.9 \%$ of a SD, and increases anxiety symptoms by $1.4-3 \%$ of a SD, though the benefit impacts on anxiety and hyperactive/inattentive symptoms are much less precisely estimated. Again, the estimated benefit effects are qualitatively similar for 19-25-year-olds (lower panel of Table 5).

Given the overall effect of disability benefits (i.e. a decline of $2-4 \%(19-21)$ to $1.6-2 \%(19-25)$ of a SD in PSE access rates in response to a $\$ 1,000$ cut in disability benefits), the above results imply that a one SD increase in math test score is associated with an rise in college attendance by $0.5-2.7 \%$ and $0.4-1.3 \%$ of a SD, equivalent to $0.2-1.3$ and $0.2-0.6$ percentage points, respectively, by the age of 21 and 25. Magnitudes are comparable for anxiety symptoms $(0.7-2.9 \%$ of a SD or 0.3-1.4 percentage points among 19-21-year-olds) and line up reasonably well with prior evidence - e.g. Carneiro, Crawford and Goodman (2007).

\section{Whose benefits matter most, when?}

7.1. Does the benefit effect vary according to whether the father or the mother is disabled?

Panel A of Table 6 shows how the estimated benefit effect on PSE attendance differs by the gender of disabled parent for our two windows of observation (19-21 left panel; 19-25 right panel). To obtain the cleanest estimates possible, we exclude youths who lived with two disabled parents, which results in a sample size reduction of approximately $2 \%$. Paternal and maternal disabilities are each identified by their incidence (columns 1-2 and 5-6) and severity (columns3-4 and 7-8).

We find a statistically significant benefit effect for paternal but not maternal disability. The magnitude of benefit effect for youth of disabled fathers is more than two times as large as that for youth overall (i.e. $4.7-12.1 \%$ of a SD by 21 and $4.1-10.6 \%$ by 25 using the preferred measures) suggesting that the adverse impact of benefit cuts on PSE is mainly concentrated on youth in families where the father is disabled (which can be explained by the disability of the father having a larger impact on a household's material living standards than that of the mother, since male wages tend to be higher). Given that households where the father is disabled have a lower average income than those in which the mother is disabled, this implies that income gains have a larger impact on a youth's choice of PSE lower down the income distribution.

In our earlier work (Chen, Osberg and Phipps, 2015), we found a larger effect on test scores and behavioural problems for high school aged children with a disabled mother than with a disabled father. However, because post-secondary schooling in Canada is not free, family financial circumstances (in which father's disability plays a larger role) matter more for choices such as

\footnotetext{
${ }^{30}$ For these regressions, we use a slightly different set of covariates to reflect factors relevant to these earlier child outcomes. These include child's school grade (K through ten), child age in months, child age in months squared, gender, relative age for grade, number of siblings living in the household, family structure, both parents' ages and age squared, immigration status, education, and interaction terms between both parents' education and disability statuses.
} 
college attendance, irrespective of the child's performance on standardized tests and non-cognitive skills during secondary school (see Coelli 2005 and 2006; Frenette 2007). As well, results obtained when observing children at a substantially older age, on average, in this study than they are in Chen, Osberg and Phipps, 2015 (12 vs. 10 years old) may also reflect the diminished importance of maternal income for children at different developmental stages. Panel B of Table 6 investigates these possibilities by applying the same methodology to standardized math test score, the most frequently measured intermediate outcome for youth in our sample. Our preferred estimates (column 3 and 7) find statistically significant results for children in both types of households, individually $(p<0.10)$ and jointly $(p<0.01)$, consistent with both hypotheses posited earlier. Given that the coefficient on paternal disability is only about half as large as for maternal disability, we conclude that at least part of our results are driven by different underlying mechanisms across outcomes.

\subsection{Does child age matter?}

Is there a critical developmental stage during which additional parental disability benefits produce larger gains in PSE participation? The longitudinal nature of the NLSCY enables us to ask whether it matters when in a youth's life additional income appears. To assess this, we limit ourselves to the sub-samples of 19-21 and 19-25 years olds that randomly keep one observation per youth, since a youth can be observed different numbers of times depending on his or her birth cohort (see Section 3.2). We augment our original model specification in Table 4 with the interaction of child age, parental disability and disability benefit level, where a child's age is measured in years (5-15) at the time when the parent's disability status was reported.

To allow for differential trends specific to childhood stages, we include in the regression all lower order interactions among parental disability, disability benefit level, and child age. We expect, if some stages of childhood are particularly crucial for child development, and therefore low income or related risks at these times have deeper consequences for PSE attendance, that the coefficient on the interaction between benefit eligibility and child age will be statistically significant. Detailed results are reported in Online Appendix C. Modelling child age as a continuous variable reveals that the favorable disability benefit effect on achievement diminishes with age, with each additional year associated with $0.6-1.4 \%$ of a SD of PSE attendance, according to our preferred benefit eligibility measures. Breaking the child age variable down into four categories of developmental stage (columns 2 and 4) suggests that receiving additional benefits when the child is young ( 5 to 7 years) or in early adolescence (10 to 13 years) has a larger effect on PSE attendance than if higher benefits are received during later adolescence (14 to 15 years). ${ }^{31}$

\section{Policy Implications and Discussions}

This study examines whether more transfer income helps reduce the gap in postsecondary attainment of children disadvantaged by the disability of their parents. Following a subsample of children in the NLSCY, we ask whether the level of provincial disability benefits affects the gap

\footnotetext{
${ }^{31}$ A limitation of our data is that our estimates may mingle the short and long-term/cumulative impacts of disability benefits on PSE attendance, given that youth with short and long exposure to benefit changes are indistinguishable in a cross-sectional analysis. Because the NLSCY did not ask parents' disability status in 1996 and 1998, and did not have any retrospective questions in the survey on the length of a disability, we are also unable to differentiate length from timing effects of disability benefits without knowledge of the entire history of both parents' disability, preferably from when the child is born.
} 
in PSE attendance between the children of non-disabled and disabled parents within provinces. Overall, our intention-to-treat estimates suggest that a $\$ 1,000$ benefit cut when the child is aged 515 years lowers the probability that he or she will attend PSE by $2-4 \%$ of a SD (by age 21 ) and $1.6-2 \%$ (by age 25 ). The benefit effect size is larger with each additional domain in which the parent is limited and when both parents have work-limiting disabilities. Results are robust to alternative counterfactual comparision groups (e.g., we find no effect if either parent has a university degree), data samples (e.g., 19-21- and 19-25-year-olds), and model specifications (e.g., placebo regressions controlling for concurrent policies that vary by province and year). Given that not all eligible households actually receive the benefits ascribed to them in our analysis, these figures constitute lower bound estimates of the impacts of disability benfits.

Our data suggest that one plausible pathway from disability benefit levels to post-secondary attendance may be through the impact of lower benefits on the cumulative development of children/youth before the age of 15 . We find, for example, lower standardized math test scores and increases in parent-reported anxiety symptoms associated with lower disability benefits. Our results are consistent with credit constraints facing families in which the father is disabled influencing the resources required to finance post-secondary education.

While data limitations do not allow us to draw definite conclusions, there is suggestive evidence implying a larger benefit effect in the younger age periods (i.e. 5 to 13 years) on subsequent PSE compared to impacts later in childhood (i.e. 14 to 15 years). This is consistent with child development being a cumulative process. If substantiated, it suggests that the level of disability transfers avaiable early in a child's life may be particularly important for chances of PSE participation.

We do not want to over-inflate our results - only a minority of Canadian children grow up with disabled parents and a majority of them do attend post-secondary education. But this is a smaller majority than for the children of non-disabled parents. Although our results indicate that the disability benefit level is not a determinant of PSE enrolment if the parents are themselves university educated, we find consistent evidence that when the parents are not university educated the level of disability benefit does causally affect the probability of their children's PSE attendance.

Many children of disabled parents are able to surmount the disadvantages of their childhoods. However, since children do not get to choose the disability status of their parents, the continuing outcome gap between the children of disabled and non-disabled parents is also a clear example of inequality of opportunity. Although some inequalities of opportunity may be intractably difficult for public policy to address, this paper provides evidence that for the children of disabled parents, money matters - the level of social assistance benefits reduces their outcome gap in post secondary education attainment. Continuing deficits in parental time and energy are likely always to somewhat disadvantage children whose parents are disabled, but our results indicate that the level of cash transfers via provincial disability benefits can help to lessen the gap in PSE enrolment and thereby can make a significant difference to child life chances.

To be specific, we suggest that an increase of $\$ 3,000$ per year in provincial social assistance benefits to children in families with disabled parents has the potential to close about half the outcome gap in PSE enrolment. In 2008, the final year of our analysis, we calculate that the cost of providing an increase of $\$ 3,000$ to all families with parental disabilities would have been, very 
This is an author-produced, peer-reviewed version of this article. The final, definitive version of this document can be found online at Canadian Journal of Economics, published by Wiley on behalf of the Canadian Economics Association Copyright restrictions may apply. doi: 10.1111/ caje. 12408

roughly, about $0.05 \%$ of GDP ${ }^{32}$ - which does seem to us to be an amount that Canada could afford. In general, it does not take all that much to make a big difference in the lives of people who have little - and it seems to us that the children in families dependent on parental disability benefits have a reasonable claim to greater equality of opportunity.

\section{References}

Akee, R. K., W. E. Copeland, G. Keeler, A. Angold and E. J. Costello (2010) 'Parents' Incomes and Children's Outcomes: A Quasi-Experiment," American Economic Journal: Applied Economics 2(1), 86-115

Akee, R., E. Simeonova, E. J. Costello and W. Copeland (2015) "How Does Household Income Affect Child Personality Traits and Behaviors?" National Bureau of Economic Research No. W21562

Aizer, A., S. Eli, J. P. Ferrie and A. Lleras-Muney (2014) 'The Long Term Impact of Cash Transfers to Poor Families," National Bureau of Economic Research No. w20103

Burton, P., K. Chen, L. Lethbridge and S. Phipps (2014) "Child Health and Parental Paid Work," Review of Economics of the Household Mar, 1-24

Burton, P., and S. Phipps (2009) "Economic Costs of Caring for Children with Disabilities in Canada," Canadian Public Policy 35(3), 269-290

Cameron, A. C., J. B. Gelbach and D. L. Miller (2008) "Bootstrap-Based Improvements for Inference with Clustered Errors,"

The Review of Economics and Statistics, 90(3), 414-427

Carneiro, P., C. Crawford and A. Goodman (2007) "The Impact of Early Cognitive and Non-Cognitive Skills on Later

Outcomes," Centre for the Economics of Education DP92

Carneiro, P., and J. J. Heckman (2002) "The Evidence on Credit Constraints in Post-Secondary Schooling," The Economic Journal 112(482), 705-734

Clark-Kauffman, E., G. J. Duncan and P. Morris (2003) “How Welfare Policies Affect Child and Adolescent Achievement,” The American Economic Review 93(2), 299-303

Bratti, M., and M. Mariapia (2011) "Parental Health and Child Schooling," University of Milano-Bicocca, Department of Economics Working Papers

Chen, K., N. Fortin and S. Phipps (2015) "Young in Class: Implications for Inattentive/Hyperactive Behavior of Canadian Boys and Girls." Canadian Journal of Economics 48(5), 1601-1634

Chen, K., L. Osberg and S. Phipps (2015) "Inter-Generational Effects of Disability Benefits: Evidence from Canadian Social Assistance Programs," Journal of Population Economics 28(4), 873-910

Conger, K. J., M. A. Reuter and R. D. Conger (2000) "The Role of Economic Pressure in the Lives of Parents and their Adolescents: The Family Stress Model.” In Negotiating Adolescence in Times of Change, pp. 201-223, eds. L. J. Crockett and R. K. Silbereisen. Cambridge: Cambridge University Press

Cunha, F., J. J. Heckman and S. M. Schennach (2010) "Estimating the Technology of Cognitive and Noncognitive Skill Formation," Econometrica 78(3), 883-931

Dahl, G. B., and L. Lochner (2012) "The Impact of Family Income on Child Achievement: Evidence from the Earned Income Tax Credit," American Economic Review, 102(5), 1927-1956.

Duncan, G. J., J. Brooks-Gunn and P. K. Klebanov (1994) "Economic Deprivation and Early Childhood Development," Child Development 65, 296-318

Duncan, G. J., K. Magnuson and E. Votruba-Drzal (2014) “Boosting Family Income to Promote Child Development,” The Future of Children 24(1), 99-120

Finnie, R., M. Frenette, R. Mueller and A. Sweetman (2010) "Who goes? Who stays? What matters?: Accessing and Persisting in Post-Secondary Education in Canada," Institute for Research on Public Policy

Haveman, R., B. Wolfe and J. Spaulding (1991) "Childhood Events and Circumstances Influencing High School Completion," Demography 28(1), 133-157

Haveman, R., and B. Wolfe (2000) “The Economics of Disability and Disability Policy,” Handbook of Health Economics 1(18), 995-1051

32 In 2008, the total disability assistance provincial caseload from nine disability benefit programs (New Brunswick not available) was 536,909. Assuming a proportionate case load in New Brunswick implies a national case load of roughly 550,000. If half of households receiving disability benefits have children, a $\$ 3,000$ disability benefit increase for such families implies an additional total expenditure of roughly \$ 820 million nationally. Since GDP in 2008 was \$1,551 billion (CANSIM Table 3790029), this would be equivalent to $0.053 \%$ of GDP. 
This is an author-produced, peer-reviewed version of this article. The final, definitive version of this document can be found online at Canadian Journal of Economics, published by Wiley on behalf of the Canadian Economics Association Copyright restrictions may apply. doi: 10.1111/ caje. 12408

Lefebvre, P., P. Merrigan and M. Verstraete (2008) "The Effects of School Quality and Family Functioning on Youth Math Scores: A Canadian longitudinal analysis," Cahier de recherche/Working Paper

MacKinnon, J. G., and M. D. Webb (2017) Wild Bootstrap Inference for Wildly Different Cluster Sizes," Journal of Applied Econometrics 32(2), 233-254

Meyer, B. D., W. K. Mok and J. X. Sullivan (2009) “The Under-Reporting of Transfers in Household Surveys: Its Nature and Consequences," National Bureau of Economic Research No. w15181

Mayer, S. (1997) “What Money Can't Buy: Family Income and Children's Life Chances," Cambridge, Mass: Harvard University Press

McLoyd, V. (1990) “The Impact of Economic Hardship on Black Families and Children: Psychological Distress, Parenting and Socioemotional Development," Child Development 61(2), 311-46

Milligan, K., and M. Stabile (2011) "Do Child Tax Benefits Affect the Well-Being of Children? Evidence from Canadian Child Benefit Expansions," American Economic Journal: Economic Policy 3(3), 175-205

Morefield, B. (2011) "Parental Health Events and Children's Skill Development," University of North Carolina at Greensboro, Department of Economics Working Papers

Mühlenweg, A. M., F. G. Westermaier and B. Morefield (2015) "Parental Health and Child Behavior: Evidence from Parental Health Shocks," Review of Economics of the Household 14(3), 577-598

Organisation for Economic Co-operation and Development (2010) "Sickness, disability and work: Breaking the barriers: A synthesis of findings across OECD countries," OECD Publishing

Rege, M., K. Telle and M. Votruba (2011) "Parental Job Loss and Children's School Performance," The Review of Economic Studies 78(4), 1462-1489

Roodman, R., J. G. MacKinnon, M. Ø. Nielsen and M. Webb (2018) "Fast and Wild: Bootstrap Inference in Stata using boottest," Queen's Economics Department Working Paper

Statistics Canada (2015) "A Profile of Persons with Disabilities among Canadians Aged 15 Years or Older, 2012," Catalogue no. 89-654-X. http://www.statcan.gc.ca/pub/89-654-x/89-654-x2015001-eng.pdf. Accessed on June 20, 2017

Statistics Canada (2008) "Microdata User Guide: National Longitudinal Survey of Children and Youth Cycle 8."

http://sda.chass.utoronto.ca/sdaweb/dli/nlscy/snlscy8ecd/more doc/nlscy ug8 english.pdf. Accessed on December 20, 2018

Stevens, A. H., and J. Schaller (2011) "Short-Run Effects of Parental Job Loss on Children's Academic Achievement."

Economics of Education Review 30(2), 289-299

Todd, P. E., and K. I. Wolpin (2007) "The Production of Cognitive Achievement in Children: Home, School, and Racial Test Score Gaps.” Journal of Human Capital 1(1): 91-36 
TABLE 1

Real Maximum Annual Disability Benefits (2008 \$)

\begin{tabular}{|c|c|c|c|c|c|c|c|c|c|c|c|}
\hline & NL & PEI & NS & NB & QB & ON & $\mathrm{MB}$ & SK & $\mathrm{AB}$ & $\mathrm{BC}$ & Canada \\
\hline 1994 & 10,945 & 12,192 & 11,499 & 10,736 & 10,468 & 15,338 & 10,980 & 11,465 & 14,125 & 11,674 & 11,942 \\
\hline 2000 & 10,325 & 10,515 & 10,760 & 8,337 & 10,568 & $\dddot{14,101}$ & 9,783 & 10,226 & 12,786 & 11,178 & 10,858 \\
\hline 2002 & 10,123 & 10,681 & 9,630 & 8,223 & 10,493 & $\begin{array}{c}\ldots \\
13,299\end{array}$ & 9,403 & 9,999 & 12,689 & 11,014 & 10,555 \\
\hline 2004 & 9,639 & 10,052 & 9,598 & 8,253 & 10,463 & 12,693 & 9,101 & 9,688 & 11,771 & 10,561 & 10,182 \\
\hline 2006 & 10,044 & 9,579 & 9,251 & 8,285 & 10,392 & 12,497 & 8,948 & 9,334 & 12,685 & 11,027 & 10,204 \\
\hline 2008 & 10,878 & 8,623 & 9,088 & 8,275 & 10,500 & 12,382 & 9,026 & 9,772 & 12,762 & 11,125 & 10,243 \\
\hline Real \% change, 1994-2008 & -0.61 & -29.27 & -20.97 & -22.93 & 0.30 & -19.27 & -17.79 & -14.77 & -9.65 & -4.70 & -14.23 \\
\hline $\begin{array}{l}\text { \% difference from national average, } \\
1994\end{array}$ & -10.34 & 0.89 & -3.37 & -12.07 & -17.91 & 22.47 & -9.06 & -5.33 & 22.11 & -7.77 & -- \\
\hline $\begin{array}{l}\% \text { difference from national average, } \\
2000\end{array}$ & -6.92 & -1.30 & -1.13 & -24.34 & -8.18 & 23.02 & -14.20 & -9.28 & 23.01 & -2.80 & -- \\
\hline $\begin{array}{l}\% \text { difference from national average, } \\
2002\end{array}$ & -4.01 & -1.29 & -7.85 & -19.81 & -4.73 & 20.28 & -13.77 & -8.06 & 17.51 & 0.92 & -- \\
\hline $\begin{array}{l}\% \text { difference from national average, } \\
2004\end{array}$ & -5.24 & -2.98 & -6.07 & -18.07 & -0.69 & 20.31 & -11.37 & -6.76 & 11.06 & 1.37 & -- \\
\hline $\begin{array}{l}\% \text { difference from national average, } \\
2006\end{array}$ & -2.60 & -7.03 & -10.93 & -11.59 & -2.51 & 17.04 & -14.65 & -12.13 & 17.71 & 4.11 & -- \\
\hline $\begin{array}{l}\% \text { difference from national average, } \\
2008\end{array}$ & 6.20 & -15.29 & -12.07 & -20.89 & -1.67 & 15.76 & -14.26 & -8.48 & 18.51 & 5.26 & \\
\hline Provincial Average & 10,326 & 10,274 & 9,971 & 8,685 & 10,481 & 13,385 & 9,540 & 10,081 & 12,803 & 11,096 & 10,664 \\
\hline
\end{tabular}

NOTES: Data are collected from various issues of Welfare Incomes (1993-2007). Disability benefits are the sum of the basic assistance rate (i.e., amounts for food, clothing, shelter and utilities, personal and household needs), additional benefits (i.e., supplementary allowances that were automatically provided to persons with a disability), and the provincial tax credit and GST credit intended for the disabled. Estimates assume a single disabled person who: (1) qualifies for long-term rates of assistance; (2) lives in the largest urban area in the province or territory; (3) goes on disability benefits on January 1 of each year and remains on benefits for the entire calendar year; and (4) is a tenant in the private rental market rather than a homeowner or social housing tenant, who does not share accommodation. All benefits are converted into 2008 dollars using the corresponding provincial seasonally adjusted Consumer Price Index (2011 basket content) from Statistics Canada's CANSIM (database) Table 326-0021: http://www5.statcan.gc.ca/cansim/homeaccueil?lang=eng, accessed 4 April, 2014. 
This is an author-produced, peer-reviewed version of this article. The final, definitive version of this document can be found online at Canadian Journal of Economics, published by Wiley on behalf of the Canadian Economics Association Copyright restrictions may apply. doi: 10.1111/ caje. 12408

TABLE 2

Means/Frequencies of Key Independent Variables

\begin{tabular}{|c|c|c|c|}
\hline \multicolumn{2}{|c|}{ Panel A: NLSCY } & \multicolumn{2}{|c|}{ Panel B: Canadian Survey on Disability } \\
\hline Nature of Condition & $\begin{array}{l}\text { Narrow Range 19-21 } \\
(\mathrm{N}=5,400)\end{array}$ & Nature of Condition & $\begin{array}{l}\text { All Canadians Aged } 15 \text { or } \\
\text { Older }(\mathrm{N}=27,516,200)\end{array}$ \\
\hline Either Parent Disabled & $16.3 \%$ & Individual Disabled & $13.7 \%$ \\
\hline Number of Restricted Domains & & Global Severity Class & \\
\hline$=1$ & $4.3 \%$ & Mild Disabilities & $4.3 \%$ \\
\hline$=2$ & $3.9 \%$ & Moderate Disabilities & $2.7 \%$ \\
\hline$=3$ & $5.0 \%$ & Severe Disabilities & $3.8 \%$ \\
\hline$=4$ & $3.1 \%$ & Very Severe Disabilities & $3.6 \%$ \\
\hline Working-Limiting Disability & $9.7 \%$ & -- & -- \\
\hline Gender of Disabled Parent & & Gender of Disabled Individua & \\
\hline Only Father Disabled & $6.9 \%$ & Men Disabled & $6.2 \%$ \\
\hline Number of restricted domains & $1.6 \%$ & Mild Disabilities & $2.0 \%$ \\
\hline \multicolumn{4}{|l|}{ ( } \\
\hline$=2$ & $1.9 \%$ & Moderate Disabilities & $1.2 \%$ \\
\hline$=3$ & $2.2 \%$ & Severe Disabilities & $1.3 \%$ \\
\hline$=4$ & $1.2 \%$ & Very Severe Disabilities & $1.2 \%$ \\
\hline Only Mother Disabled & $7.4 \%$ & Women Disabled & $7.6 \%$ \\
\hline Number of restricted domains & $2.5 \%$ & Mild Disabilities & $2.3 \%$ \\
\hline \\
\hline$=2$ & $1.6 \%$ & Moderate Disabilities & $1.5 \%$ \\
\hline$=3$ & $2.0 \%$ & Severe Disabilities & $1.8 \%$ \\
\hline$=4$ & $1.3 \%$ & Very Severe Disabilities & $2.0 \%$ \\
\hline Both Parents Disabled & $2.0 \%$ & -- & -- \\
\hline
\end{tabular}

NOTES: Panel A reports the percentages of youth living with disabled parents by disability incidence, severity, and the gender of the disabled parent for the narrower age range. The sample consists of non-disabled youth living in two-parent families, whose parents were less than 65 years of age and did not have a university degree Panel B provides national averages on disability prevalence using data from the 2012 Canadian Survey on Disability (CSD). Note that because the unit of analysis of the CSD is adult whereas our unit of analysis is a youth with parents aged less than 65, the rates of disability presented in these two panels will differ due to differences in population coverage and sampling weights as well as disability definitions. 
This is an author-produced, peer-reviewed version of this article. The final, definitive version of this document can be found online at Canadian Journal of Economics, published by Wiley on behalf of the Canadian Economics Association Copyright restrictions may apply. doi: 10.1111/ caje. 12408

TABLE 3

Means/Frequencies of Covariates

\begin{tabular}{|c|c|c|c|c|}
\hline & $\begin{array}{l}\text { Non-Disabled } \\
\text { Parents }\end{array}$ & $\begin{array}{l}\text { Disabled } \\
\text { Parents }\end{array}$ & $\begin{array}{c}\text { Parents with } \\
\text { Single Disability }\end{array}$ & $\begin{array}{c}\text { Parents with } \\
\text { Multiple } \\
\text { Restricted } \\
\text { Domains } \\
\text { (4) }\end{array}$ \\
\hline \multicolumn{5}{|c|}{ Panel A: Variables Measured at the First Observation When Child Aged 5 to 15 Years } \\
\hline \multicolumn{5}{|l|}{ Gender } \\
\hline Boy & $51.5 \%$ & $52.3 \%$ & $51.5 \%$ & $51.8 \%$ \\
\hline Girl & $48.5 \%$ & $47.7 \%$ & $48.5 \%$ & $48.2 \%$ \\
\hline Siblings & 1.41 & 1.45 & 1.53 & 1.42 \\
\hline Child age & 12.75 & 12 & 11.3 & 12 \\
\hline School grade & 4.03 & 5.02 & 4.73 & 5.36 \\
\hline Relative age for grade & $46.2 \%$ & $44.9 \%$ & $40.7 \%$ & $46.2 \%$ \\
\hline \multicolumn{5}{|l|}{ Mother education } \\
\hline Some postsecondary & $24.5 \%$ & $25.1 \%$ & $22.8 \%$ & $24.7 \%$ \\
\hline High school & $58.5 \%$ & $54.7 \%$ & $60.5 \%$ & $53.9 \%$ \\
\hline Less than high school & $17.1 \%$ & $20.2 \%$ & $16.7 \%$ & $21.5 \%$ \\
\hline \multicolumn{5}{|l|}{ Father education } \\
\hline Some postsecondary & $25.9 \%$ & $22.8 \%$ & $30.8 \%$ & $19.5 \%$ \\
\hline High school & $52.4 \%$ & $53.6 \%$ & $50.8 \%$ & $54.4 \%$ \\
\hline Less than high school & $21.6 \%$ & $23.5 \%$ & $18.5 \%$ & $26.0 \%$ \\
\hline Either parent immigrant & $17.6 \%$ & $17.6 \%$ & $22.2 \%$ & $16.7 \%$ \\
\hline Mother age & 39.9 & 38.8 & 39.0 & 38.5 \\
\hline Father age & 42.2 & 41.6 & 41.5 & 41.3 \\
\hline Step family & $10.1 \%$ & $10.1 \%$ & $3.6 \%$ & $12.1 \%$ \\
\hline Provincial disability benefit $(\$ 1,000)$ & 12.05 & 12.25 & 12.31 & 12.26 \\
\hline \multicolumn{5}{|c|}{ Panel B: Variables Measured at the Second Observation When Youth Aged 19-21 Years } \\
\hline PSE Participation & $67.1 \%$ & $60.4 \%$ & $62.7 \%$ & $59.9 \%$ \\
\hline Change in the number of siblings & -0.61 & -0.75 & -0.78 & -0.76 \\
\hline \multicolumn{5}{|l|}{ Child age } \\
\hline 19 & $42.3 \%$ & $52.6 \%$ & $50.6 \%$ & $51.1 \%$ \\
\hline 20 & $32.4 \%$ & $27.2 \%$ & $23.2 \%$ & $30 \%$ \\
\hline 21 & $25.3 \%$ & $20.2 \%$ & $26.2 \%$ & $18.9 \%$ \\
\hline Step family & $6.4 \%$ & $7.5 \%$ & $2.7 \%$ & $8.9 \%$ \\
\hline $\mathrm{N}$ & 4520 & 880 & 230 & 650 \\
\hline
\end{tabular}

NOTES: The sample consists of non-disabled youth aged between 19 and 21 in two-parent families whose parents were less than 65 years of age and did not have any university degree. Throughout all tables, as required by Statistics Canada, All sample sizes are randomly rounded to minimize potential disclosure risk. *** Significant at the $1 \%$ level. ** Significant at the 5\% level. * Significant at the $10 \%$ level. 
TABLE 4

Estimated Parental Disability Benefit Effects on PSE Participation of Child: Parents without University Education

\begin{tabular}{|c|c|c|c|c|c|c|c|c|}
\hline & \multicolumn{4}{|c|}{ Narrow Range (19-21 years) } & \multicolumn{4}{|c|}{ Wide Range (19-25 years) } \\
\hline & \multicolumn{2}{|c|}{ Incidence } & \multicolumn{2}{|c|}{ Severity } & \multicolumn{2}{|c|}{ Incidence } & \multicolumn{2}{|c|}{ Severity } \\
\hline & $\begin{array}{l}\text { Either parent } \\
\text { has any } \\
\text { restriction } \\
\text { (1) }\end{array}$ & $\begin{array}{l}\text { Either parent } \\
\text { has work- } \\
\text { limiting } \\
\text { disability } \\
\text { (2) }\end{array}$ & $\begin{array}{l}\text { Number of } \\
\text { restricted } \\
\text { domains } \\
\text { (3) }\end{array}$ & $\begin{array}{l}\text { Number of } \\
\text { parents with } \\
\text { work-limiting } \\
\text { disability } \\
\text { (4) }\end{array}$ & $\begin{array}{l}\text { Either parent has } \\
\text { any restriction } \\
\text { (5) }\end{array}$ & $\begin{array}{c}\text { Either parent has work- } \\
\text { limiting disability } \\
\text { (6) }\end{array}$ & $\begin{array}{l}\text { Number of } \\
\text { restricted } \\
\text { domains } \\
\text { (7) }\end{array}$ & $\begin{array}{l}\text { Number of } \\
\text { parents with } \\
\text { work-limiting } \\
\text { disability } \\
\text { (8) }\end{array}$ \\
\hline BEN x Incidence & $\begin{array}{l}0.024 * * \\
{[0.043]}\end{array}$ & $\begin{array}{c}0.028 * * \\
{[0.026]}\end{array}$ & & & $\begin{array}{c}0.018^{*} \\
{[0.058]}\end{array}$ & $\begin{array}{l}0.024 * * \\
{[0.036]}\end{array}$ & & \\
\hline BEN x Severity & & & $\begin{array}{c}0.010 * * \\
{[0.028]}\end{array}$ & $\begin{array}{c}0.020 * * \\
{[0.048]}\end{array}$ & & & $\begin{array}{c}0.008 * * \\
{[0.016]}\end{array}$ & $\begin{array}{l}0.014 * \\
{[0.075]}\end{array}$ \\
\hline Step Family & $\begin{array}{c}-0.159^{* * *} \\
([0.000]\end{array}$ & $\begin{array}{c}-0.158^{* * *} \\
{[0.000]}\end{array}$ & $\begin{array}{c}-0.156^{* * *} \\
{[0.000]}\end{array}$ & $\begin{array}{c}-0.159 * * * \\
{[0.000]}\end{array}$ & $\begin{array}{c}-0.125 * * * \\
{[0.000]}\end{array}$ & $\begin{array}{c}-0.125^{* * *} \\
{[0.000]}\end{array}$ & $\begin{array}{c}-0.124 * * * \\
{[0.000]}\end{array}$ & $\begin{array}{r}-0.125^{* * * *} \\
{[0.000]}\end{array}$ \\
\hline $\begin{array}{l}\text { Mean (PSE) } \\
\text { SD (PSE) } \\
\text { N }\end{array}$ & & $\begin{array}{l}0 \\
0 \\
5\end{array}$ & & & & $\begin{array}{l}0.619 \\
0.485 \\
7900\end{array}$ & & \\
\hline
\end{tabular}

NOTES: OLS estimates of the parental disability benefit impact on PSE attendance for the youth of parents who did not have any university degree. All models control for year, province, and province-by-year fixed effects. In addition, we include two sets of covariates in the regressions. The first was measured at the time of disability, including child gender, relative age for grade, number of siblings living in the household, family structure, both parents' ages and age squared, immigration status, education, and interaction terms between both parent's education and

disability statuses. The second set was measured at college entry, including youth age, change in the number of siblings between the reports of parental disability and PSE attendance, and family structure. The mean and standard deviation reported at the bottom of the table indicate PSE participation for youth with a disabled parent. Standard errors are clustered at the province level (10 clusters). In square brackets, we report wild cluster bootstrapped P-values (1000 replications and Rademacher weights) based on Cameron, Galback and Miller (2008). *** Significant at the 1\% level; ** Significant at the $5 \%$ level; * Significant at the $10 \%$ level. 
This is an author-produced, peer-reviewed version of this article. The final, definitive version of this document can be found online at Canadian Journal of Economics, published by Wiley on behalf of the Canadian Economics Association Copyright restrictions may apply. doi: 10.1111/caje. 12408

Table 5

Pathways: Estimated Impact of Parental Disability Benefits on Cognitive, Social/Behavioral, and Emotional Outcomes

\begin{tabular}{|c|c|c|c|c|c|c|c|}
\hline & (1) & $\begin{array}{l}\text { Mean } \\
(\mathrm{PSE})\end{array}$ & $\begin{array}{l}\text { SD } \\
(\mathrm{PSE})\end{array}$ & $\begin{array}{l}\text { Incidence } \\
\text { Either parent } \\
\text { has any } \\
\text { restriction } \\
\text { (3) }\end{array}$ & $\begin{array}{l}\text { Either parent } \\
\text { has work- } \\
\text { limiting } \\
\text { disability } \\
\quad \text { (4) }\end{array}$ & $\begin{array}{l}\text { Severity } \\
\text { Number of } \\
\text { restricted } \\
\text { domains } \\
\quad \text { (5) }\end{array}$ & $\begin{array}{l}\text { Number of } \\
\text { parents with } \\
\text { work-limiting } \\
\text { disability } \\
\text { (6) }\end{array}$ \\
\hline \multicolumn{8}{|c|}{ Panel A: Narrow Range (19-21 years) } \\
\hline $\begin{array}{l}\text { Standardized Math } \\
\text { Test Score }\end{array}$ & 3140 & 505 & 109 & $\begin{array}{l}3.341 * * * \\
{[0.000]}\end{array}$ & $\begin{array}{l}4.884 * * \\
{[0.037]}\end{array}$ & $\begin{array}{l}1.725 * * \\
{[0.028]}\end{array}$ & $\begin{array}{l}4.294 * \\
{[0.065]}\end{array}$ \\
\hline $\begin{array}{l}\text { Emotional Anxiety } \\
\text { Scale }\end{array}$ & 2660 & 2.603 & 2.493 & $\begin{array}{l}-0.105 * * * \\
{[0.001]}\end{array}$ & $\begin{array}{l}-0.058 * \\
{[0.096]}\end{array}$ & $\begin{array}{l}-0.034 \\
{[0.259]}\end{array}$ & $\begin{array}{l}-0.075 * \\
{[0.098]}\end{array}$ \\
\hline $\begin{array}{l}\text { Hyperactive/ } \\
\text { Inattentive Scale }\end{array}$ & 2660 & 3.881 & 3.131 & $\begin{array}{l}0.003 \\
{[0.956]}\end{array}$ & $\begin{array}{l}0.025 \\
{[0.743]}\end{array}$ & $\begin{array}{l}0.010 \\
{[0.811]}\end{array}$ & $\begin{array}{l}0.011 \\
{[0.807]}\end{array}$ \\
\hline \multicolumn{8}{|c|}{ Panel B: Wide Range (19-25 years) } \\
\hline $\begin{array}{l}\text { Standardized Math } \\
\text { Test Score }\end{array}$ & 3590 & 508 & 110 & $\begin{array}{l}3.179 * * * \\
{[0.001]}\end{array}$ & $\begin{array}{l}4.847 * * \\
{[0.026]}\end{array}$ & $\begin{array}{l}1.808 * * * \\
{[0.005]}\end{array}$ & $\begin{array}{l}4.421 * * \\
{[0.039]}\end{array}$ \\
\hline $\begin{array}{l}\text { Emotional Anxiety } \\
\text { Scale }\end{array}$ & 3310 & 2.521 & 2.557 & $\begin{array}{l}-0.105 * * * \\
{[0.009]}\end{array}$ & $\begin{array}{l}-0.066 \\
{[0.477]}\end{array}$ & $\begin{array}{l}-0.038 \\
{[0.157]}\end{array}$ & $\begin{array}{l}-0.083 \\
{[0.206]}\end{array}$ \\
\hline $\begin{array}{l}\text { Hyperactive/ } \\
\text { Inattentive Scale }\end{array}$ & 3310 & 3.816 & 3.378 & $\begin{array}{l}-0.032 \\
{[0.455]}\end{array}$ & $\begin{array}{l}-0.006 \\
{[0.938]}\end{array}$ & $\begin{array}{l}0.001 \\
{[0.997]}\end{array}$ & $\begin{array}{l}0.021 \\
{[0.724]}\end{array}$ \\
\hline
\end{tabular}

NOTES: 1. The table shows the estimated impacts of parental disability benefits on children's cognitive, behavioral, and emotional well-being outcomes, as measured by standardized math test score, parent-report hyperactive/inattentive and emotional anxiety symptoms. A higher value of the hyperactivity and anxiety scores indicates worse outcomes -- see text for more details. 2. All models control for year, province, and province-by-year fixed effects. In addition, we include two sets of covariates in the regressions. 3. The covariates controlled in all regressions but are not reported include child age in month, child age squared, gender, relative age for grade, number of siblings living in the household, family structure, both parents' ages and age squared, immigration status, education, and interaction terms between both parents' education and disability statuses. Since the difficulty of the math test in the NLSCY varies with the school grade of the child, the standardized scores increases as a child grows older (Lefebvre, Merrigan and Verstraete 2008). We additionally control for parent-reported school grade ( $\mathrm{K}$ through ten) for the child in our math test score regressions. 4 . The mean and standard deviation indicate those of the dependent variable used in the regression. 5. Standard errors are clustered at the province level (10 clusters). In square brackets, we report wild cluster bootstrapped P-values (1000 replications and Rademacher weights) based on Cameron, Galback and Miller (2008) *** Significant at the 1\% level; ** Significant at the 5\% level; * Significant at the 10\% level. 
TABLE 6

Heterogeneous Effects on PSE Participation: Paternal Vs. Maternal Disabilities.

Narrow Range (19-21 years)

$$
\text { Incidence }
$$

Either parent has Either parent has work- Severity

Number of restrict
domains

$$
\text { (2) }
$$

(3)

Panel A: PSE Attendance

\begin{tabular}{lcc} 
& \multicolumn{2}{c}{ Panel A: PSE Attendance } \\
BEN x Father DIS & $0.051^{* * *}$ & $0.055^{* * *}$ \\
& {$[0.008]$} & {$[0.006]$} \\
Ben x Mother DIS & 0.012 & 0.002 \\
& {$[0.657]$} & {$[0.940]$}
\end{tabular}

F-Statistics \& P-Values on Joint Hypothesis BEN x Father DIS, 15.400

BEN x Mother DIS $=0$

$$
\begin{aligned}
& 15.400 \\
& {[0.026}
\end{aligned}
$$

\begin{abstract}
12.166
\end{abstract}
[0.020]

5300

$\mathrm{N}$

Panel B: Standardized Math Test Score

BEN x Father DIS

$$
3.692
$$

[0.130]

4.784

3.698

Ben x Mother DIS

[0.389]

[0.159]

$9.269^{* * *}$

[0.027]

$0.023 * * *$
$[0.006]$
0.007
$[0.453]$

[0.453]

17.970

[0.008]

$1.754^{*}$
$[0.070]$
$2.799^{*}$
$[0.098]$

$$
6.774
$$

62.070

BEN x Father DIS,

[0.001]

[0.003]

\begin{abstract}
14.060
\end{abstract}
[0.006]

3500

$\mathrm{N}$

NOTES: 1.The table shows the effects of parental disability benefits on PSE participation (Panel A) and math test scores (Panels B) breaking down by the gender of the disabled parent for the youth of parents who did not have any university degrees. We exclude youths lived with two disabled parent in the two age ranges from the analysis for easy of interpretation. 2. The covariates controlled in all regressions are identical to those in Table 5. 3. The mean and standard deviation of the PSE participation are shown for children lived with a disabled parent. 4. Standard errors are clustered at the province level (10 clusters). In square brackets, we report wild cluster bootstrapped P-values (1000 replications and Rademacher weights) based on Cameron, Galback and Miller (2008). *** Significant at the $1 \%$ level; ** Significant at the $5 \%$ level; * Significant at the $10 \%$ level. 
This is an author-produced, peer-reviewed version of this article. The final, definitive version of this document can be found online at Canadian Journal of Economics, published by Wiley on behalf of the Canadian Economics Association Copyright restrictions may apply. doi: 10.1111/caje.12408

(a) PSE Participation (19-21 year olds)

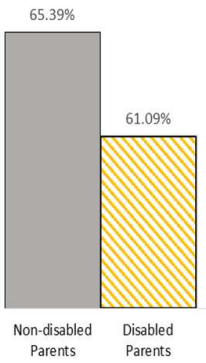

(b) Standardized Math Test Score $\left(2^{\text {nd }}-10^{\text {th }}\right.$ Graders $)$

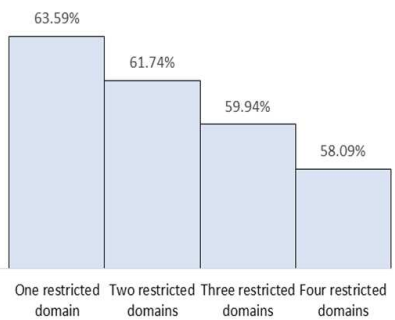

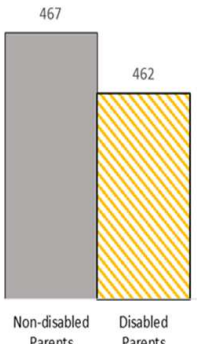

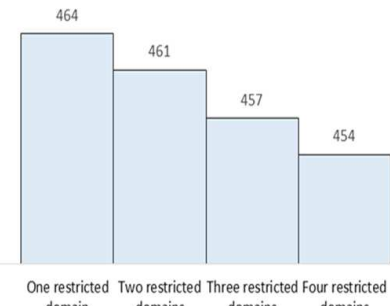

(c) Parent-report hyperactive/inattentive symptoms (5-11 year olds)
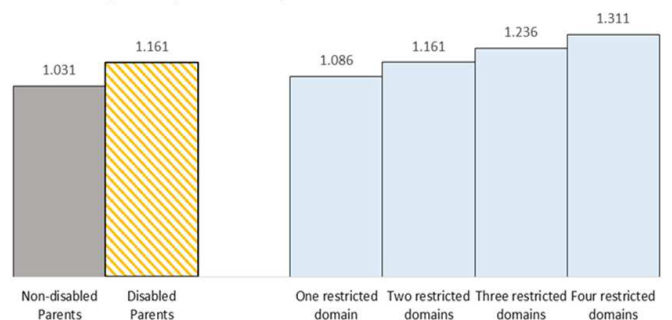

(d) Parent-report anxiety symptoms (5-11 year olds)
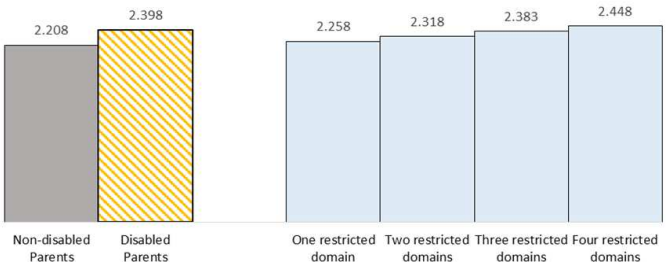

FIGURE 1

PSE Participation and Intermediate Outcomes by Number of Functional Domains in Which Parent Is Limited

NOTES: Figure 1.a shows the predicted probabilities of PSE participation adjusting age and gender for NLSCY youth aged 19-21. The probabilities are computed for a hypothetical youth with the mean age of the sample (i.e. 21 when participation in PSE is assessed). Figures 1.b-d show the age- and gender-adjusted math test score, hyperactive/inattentive and anxiety symptoms for the same youth when they were in grades 2-10 and 5-11 year old, respectively. For math test scores, we additionally control for the child's school grade at the time of the test (details see Data section). All outcomes are computed for a hypothetic child with the mean age and if applicable, school grade (i.e. 4th grade when parental disability is assessed) of the sample. 